\title{
REPENSANDO LAS CONSECUENCIAS BIOÉTICAS DEL MONISMO Y EL DUALISMO: EL EMERGENTISMO SISTÉMICO COMO PERSPECTIVA EPISTÉMICA SUPERADORA DEL TOTALITARISMO
}

\begin{abstract}
Francisco López-Muñoz ${ }^{1}$ Francisco Pérez-Fernández ${ }^{2}$
Resumen: La comprensión de la conciencia ha sido durante siglos uno de los caballos de batalla del devenir intelectual, en tanto contexto en el que se han definido y redefinido las diferentes percepciones socioculturales, científicas, filosóficas e ideológicas del ser humano. Lejos de tratarse de un problema superado, se trata de una cuestión que, reformulada una y otra vez, en distintos ámbitos y contextos, retorna sin cesar al epicentro del debate intelectual, dadas sus consecuencias epistémicas y necesariamente éticas. En este trabajo se trata de mostrar cómo tal debate y sus posturas se alimentan de una percepción que se estima "anticuada" del problema, al afrontarlo desde una óptica esencialista (cifrada sobre un modelo de pensamiento basado en esquemas de razón-objeto), a la par que se propone una reformulación de la cuestión en términos procesuales, inspirada en la propuesta del emergentismo sistémico. Con ello, se pretende aportar un enfoque superador de un modelo intelectual que se estima obsoleto, a la par que se propicia una reflexión ética en torno a las consecuencias intelectuales ideológicas y prácticas devenidas de un sostenimiento artificioso del mismo en el ámbito de la ciencia.
\end{abstract}

Palabras clave: emergentismo sistémico, epistemología, dualismo, reduccionismo, totalitarismo

Rethinking the bioethical consequences of monism and dualism: Systemic emergentism as an epistemic perspective that overcomes totalitarianism

\begin{abstract}
For centuries, the understanding of conciousness has been one of the topic issues of intellectual development, and a context in which the different sociocultural, scientific, philosophical and ideological perceptions of the human being have been defined and redefined. Far from being a solved problem, it's a theme that, reformulated again and again in different fields and contexts, returns endlessly to the epicenter of intellectual discussion because it has, necessarily, trascendental epistemic and ethical consequences. This paper tries to show how such confrontation and its positions are fed by an "outdated" perception of the problem, when faced it from an essentialist perspective (encrypted on a model of thought based on reason-object schemes). Therefore is proposed a reformulation of the question in procedural terms inspired by the theory of systemic emergentism. So, it is intended to provide an overcoming approach to an intellectual model that is considered obsolete, while fostering an ethical reflection on the ideological intellectual consequences and practices derived from its artificial support in the field of Science
\end{abstract}

Key words: systemic emergentism, epistemology, dualism, reductionism, totalitarianism

Repensando as consequências bioéticas do monismo e do dualismo: o emergentismo sistêmico como perspectiva epistêmica que sobrepuja o totalitarismo

Resumo: A compreensáo de consciência tem sido, durante séculos, um dos cavalos de batalha do tornar-se intelectual, no contexto em que se definiu e se redefiniu as diferentes percepçôes socioculturais, científicas, filosóficas e ideológicas do ser humano. Longe de se tratar de um problema superado, trata-se de uma questão que, reformulada uma ou outra vez, em distintos âmbitos e contextos, retorna ao epicentro do debate intelectual, dadas suas consequências epistêmicas e necessariamente éticas. Tratamos demonstrar neste trabalho como tal debate e suas posturas alimentam-se de uma percepçáo que se estima ser "antiquada" do problema, ao enfrenta-lo a partir de uma visão essencialista (codificada sobre um modelo de pensamento baseado em esquemas de razão-objeto), ao mesmo tempo em que se propóe uma reformulação da questão em termos processuais, inspirada na proposta do emergentismo sistêmico. Com isto, pretende-se aportar um enfoque que supera um modelo intelectual que se estima obsoleto, ao mesmo tempo em que se propicia uma reflexão ética em torno das consequências intelectuais ideológicas e práticas decorrentes de um apoio artificial do mesmo no âmbito da ciência.

Palavras chave: emergentismo sistêmico, epistemologia, dualismo, reducionismo, totalitarismo

\footnotetext{
${ }^{1}$ Universidad Camilo José Cela, Madrid, España. Unidad de Neuropsicofarmacología, Instituto de Investigación Hospital 12 de Octubre (i+12), Madrid, España. Portucalense Institute of Neuropsychology and Cognitive and Behavioural Neurosciences (INPP), Universidade Portucalense, Oporto, Portugal

Correspondencia: flopez@ucjc.edu

${ }^{2}$ Departamento de Psicología, Facultad de Ciencias de la Salud, Universidad Camilo José Cela, Madrid, Espańa
} 


\section{Introducción}

Abordar hoy un problema de poderosas implicaciones bioéticas, como la cuestión "mentecuerpo", supone encontrarse con el hándicap de afrontar un asunto propio del siglo XXI con un marco lingüístico generado en el siglo XVII, momento en el que venía delimitado por un contexto de discusión filosófico-religioso y cuyo desarrollo científico se encontraba en fase embrionaria $(1,2)$. Se olvida que, hasta la consolidación de la Psicología y la Psiquiatría contemporáneas, relativamente cercana en el tiempo, éste era un problema que se dirimía en el contexto de la metafísica. En todo caso, y se trata de un obstáculo muy extendido en el debate neuropsicológico actual, el asunto excede los límites del lenguaje, en la medida que enraíza con toda una familia de problemas de gran capacidad contaminante que el debate cartesiano localizó hábilmente, al punto de que han influido en la interpretación de los avances de la investigación empírica(2).

Sucede que este tema se desliza hacia el prejuicio intelectual y no admite debate dentro de los márgenes delimitados por el método científico: hay cosas que existen, como la identidad personal, los pensamientos y las percepciones, que se interpretan como "subjetivas e inmateriales", y frente a ellas existen cosas físicas, como el cuerpo y sus procesos, a los que se supone "objetivos y materiales". Y no hay forma de entender cómo ambos elementos se relacionan entre sí. La solución tradicional a esta dicotomía ha consistido en degradar el estatus de uno de ambos elementos hasta transformarlo en irrelevante. Y, teniendo en cuenta el éxito histórico de las ciencias físicas, biológicas y médicas, se ha arremetido contra lo mental, lo subjetivo. Por supuesto, a ello subyace una tendencia intelectual ya planteada por el positivismo decimonónico: todo aquello que no es "ciencia natural" (o sea, que no habla de cosas físicas, con masa y extensión, susceptibles de ser controladas en términos causales y de algún modo mensurables con razonable "exactitud"), no es conocimiento válido, por poco operativo(3). Tal modo de conducirse no es otra cosa que el resultado de una incapacidad epistemológica de la ciencia natural para lidiar con cuestiones que la sociedad estima prevalentes. Incapacidad surgida del hecho de que la métrica del reduccionismo a lo material, los conceptos cerrados con los que se ve obligado a trabajar, y la naturaleza misma del problema, simplemente no encajan. Por esto se ha optado por eludir estas cuestiones, o se ha argumentado que son simple ilusión, de suerte que, tarde o temprano "se resolverán" por sí mismas(4). Una tendencia posmoderna, por cierto, pues ya en los mismos fundamentos de la neurología contemporánea se advertía con notable clarividencia que el asunto de las "mariposas del alma" muy posiblemente fuera inabordable desde enfoques fisicalistas $(5,6)$.

También persiste otra tendencia, no menos perversa, y es el problema histórico de la "divinización" de la conciencia. La tesis de que lo corporal podría no ser tan importante como se defiende, y de que "lo consciente" debe prefigurar algún tipo de entidad independiente. Ello haría necesario determinar en qué sentido y hasta qué punto lo es, y por qué es necesario que lo sea. Ocurre que la existencia de un profundo vínculo cultural entre conceptos como conciencia, mente, alma y Dios incita a establecer entre ellos un sistema de vasos comunicantes. Así pues, el creyente hablará de la conciencia de un modo bastante diferente al ateo o al agnóstico, pero ninguno de ellos perderá de vista esta conexión. Además, la conciencia goza de una primacía histórico-cultural que induce a su exaltación, toda vez que se la enfrenta a cualquier fenómeno inconsciente que debiera ser contemplado como algo oscuro, incontrolado y peligroso. Quizá se trate de una de las consecuencias más obvias de esa contraposición nietzscheana entre "lo apolíneo" y "lo dionisíaco", ubicada en los cimientos de la cultura occidental(7). Lo curioso es que nunca ha existido una definición precisa del concepto "conciencia", siendo su tratamiento controvertido, en contraposición a lo que sucede con la "inconsciencia", a la que se caracteriza por mera polaridad semántica(8).

Habría, en síntesis, cuatro rasgos de los fenómenos mentales que, simplemente, no cuadran con la visión científico-tecnológico-materialista del mundo. Primeramente está lo que llamamos "conciencia" (este "darse cuenta" de lo que sucede en un momento dado); en segundo término existe la "intencionalidad" (o el hecho de que los estados mentales conscientes aludan a cosas y situaciones ajenas a ellos mismos); en tercer lugar tenemos la "subjetividad" (o el hecho de que se perciban cosas 
que nadie más puede percibir, analizar o entender); y, por último, aunque no menos importante, se da la cuestión de la "causación mental" (o pensar que los pensamientos y sensaciones importan a la hora de movilizar el comportamiento y son causa de determinados fenómenos físicos). Y cualquier explicación satisfactoria de esta cuestión debe tomar en cuenta los cuatro rasgos(1).

Cabe preguntarse cuál sería el lenguaje oportuno para acometer la empresa de redefinir el problema más allá de su lectura anticuada. Las palabras tienen una historia que las "carga" de sentidos, las reconfigura simbólicamente. La filosofía del lenguaje y la antropología cultural han establecido que el lenguaje no es aséptico, pues "utiliza" al hablante al menos en la misma medida en que éste lo utiliza. Ello implica que, al hablar de algo, ya no nos referimos a la cosa en concreto, sino también al modo en que "se habla" de ella, hecho influenciado por la infinidad de circunstancias contextuales que la afectan, por el "peso" denotativo y connotativo de las palabras empleadas, y por el modo en que podemos elaborarla cognitivamente $(9,10)$.

El problema ético aparece en forma de círculo vicioso: lo consciente (mental) y lo inconsciente o subconsciente (corporal) se definen retroactivamente, de forma antisimétrica, aludiendo a su contrario para legitimarse, a la par que degradándolo para afirmar su primacía. Así, sería atribuible a proceso mental lo que no parece reductible a actividad corporal, y sería básicamente corporal todo aquello que podría explicarse sin la intervención de algún proceso mental. Pero este planteamiento no solo es lingüística y epistemológicamente inapropiado, sino que contraviene los hechos conocidos más elementales y ahonda en las dificultades que pretende resolver, pues los límites entre lo corporal y lo mental nunca han estado claros, con las consecuencias que ello tiene para otros ámbitos de la vida(11).

\section{La propuesta del emergentismo sistémico}

Una de las paradojas científicas de los últimos cien años de investigación psicológica, ha resultado ser la ingente cantidad de tiempo y recursos dedicado a la explicación de "fenómenos conscientes" por parte de investigadores que, aparte de ser materialistas confesos, que no asumen la existencia de la conciencia como entidad independiente, además han tratado de reducirla a proceso cerebral, o a mera función ambiental, con lo cual ya no se hablaría de "conciencia" en sentido estricto, pues se excluiría alguno de los cuatro condicionantes indicados anteriormente. Posiblemente, a ello se deba que la neuropsicología haya llegado a conocer bastante bien los "automatismos" del hemisferio izquierdo del cerebro, pero haya comprendido bastante peor al hemisferio derecho a causa de la escasa claridad de sus sintomatologías, que se relacionan con los difusos problemas de la conciencia(12).

Que todo se pretenda como "neuro-algo", se quiera explicar en términos "bio" y "fisio", se disfrace tras la jerga fisiologicista de lo "emocional", o se reduzca a bioquímica, cálculo estadístico o aparatología, adentra el tema en la pseudociencia por el camino más recto: el que parte desde algún punto de la ciencia genuina, ya tratando de demostrar ciertas ideas a partir de otras posibles, pero que todavía no se han demostrado, ya partiendo de conceptos que, aun contando con ciertas evidencias que podrían llegar a corroborarlos, todavía tienen componentes especulativos. No quiere decirse que especular sea una actividad perversa. Lo que se infiere es que, por más que una hipótesis tenga visos de certeza, no deja de ser precisamente lo que es: hipótesis(8).

Desde las aportaciones realizadas durante la segunda mitad del siglo XX a la comprensión de la funcionalidad sociohistórica del conocimiento científico, no cabe caer en la ingenuidad de que la ciencia sea una entidad objetiva e inmaculada, realizada por personas que carecen de cualquier interés personal y/o corporativo, y a las que solo movería una búsqueda socrática e incansable del conocimiento $(13,14)$. Ese relato, que la cultura popular ha conducido al mito en el contexto de la creación artística, atenta contra los hechos: los científicos son personas con intereses particulares, colectivos, institucionales y empresariales, sujetas a las presiones y exigencias de la ideología, la cultura y la economía. En realidad, muchas de las posturas enfrentadas vigentes en el trasfondo del debate científico se vinculan más con exigencias ajenas al conocimiento mismo que con la defensa genuina de una "verdad"(8). No se infiere que la ciencia esté repleta de agentes del poder, puestos al servi- 
cio de oscuros intereses, pues, en condiciones sociopolíticas normales, el interés del científico suele ser "auténtico". Cosa diferente sucede cuando las condiciones distan de ser "normales" y se le induce a tomar partido por determinada causa, como sucedió, por ejemplo, en la Alemania nazi(15-17). Lo que ocurre es que el conocimiento no es neutral y las oscilaciones históricas que determinados temas de calado sociopolítico sufren, son más artificiales que basadas en evidencias experimentales genuinas(18).

La Psicología se ha venido encontrando con el acontecimiento de que estos fenómenos aparentemente antitéticos (lo consciente y lo inconsciente) se encuentran en perfecta correlación e interacción, siendo complejo determinar dónde empieza uno y termina lo otro, si es que son entes diferentes. La evolución clásica de las teorías "central" y "periférica" de la emoción es un buen ejemplo: las emociones, en tanto que mecanismos adaptativos, carecerían de sentido si tuvieran que generarse conscientemente, por cuanto se incrementaría dramáticamente la velocidad de procesamiento. Por ello, William James (1842-1910) y Carl Lange (1834-1900) postularon la teoría periférica de la emoción, por la que primero se produce una alteración somato-visceral que genera la reacción corporal apropiada y, a posteriori, tal alteración sería procesada de manera subjetiva consciente como una emoción específica(18). Tampoco es que Walter B. Cannon (1871-1945) y Philip Bard (1898-1977) se opusieran a este planteamiento, sino que lo corrigieron y ampliaron, al entender que no existía simultaneidad cognición-emoción, sino una interacción: el tálamo procesaría los estímulos externos y enviaría señales hacia estructuras superiores (corteza cerebral) e inferiores (hipotálamo), de suerte que las respuestas física y psíquica a la emoción se desencadenarían simultáneamente, variando únicamente en relación a la veloci$\operatorname{dad}(19,20)$. O sea, las emociones no estarían sujetas a un control directo de la actividad consciente y, en realidad, la acción consciente sobre ellas las interfiere, alterando su curso fisiológico. Hecho corroborado en la experiencia clínica, en la que se utiliza como facilitador terapéutico a fin de lograr “cambios" en el paciente(8).

Al hablar de mente y cuerpo como eventos correlativos y/o interactivos, y tener la obligación de explicar qué significa esto, se suscita la discusión acerca del denominado "emergentismo". Postura que, en general, defiende que ese fenómeno al que se llama de manera habitual "mente" no es otra cosa que una estructuración sistémica y especial del cerebro humano, consecuencia cualitativa directa de su evolución biológica. No parece, sin embargo, que la de "emergentismo" sea la denominación más adecuada para este enfoque, en la medida que el concepto "emerger" induce a confusión, por cuanto hace referencia al hecho de la aparición de algo que ya existía antes de salir a la superficie(21). Aceptar esta literalidad conceptual implicaría que la mente, como producto cualitativo devenido del proceso evolutivo biológico, sería un fenómeno oculto, a la espera de "salir", y ello induciría a pensarla como entidad espiritual de origen meta-humano, o bien independiente, aunque fuera de origen biológico. Sin embargo, lo que se trata de postular es que la mente es una propiedad específica y sistémica del cerebro que, aun dependiendo de él, no podría ya reducirse a su mera actividad orgánica, en la medida que una característica intrínseca a cualquier sistema es que la actividad del todo sea diferente de la actividad de sus partes. En consecuencia, entender esta propuesta implica asumir dos ideas complementarias: 1) que la estructura cerebral que posibilita los fenómenos mentales es una consecuencia de la evolución biológica, y 2) que la estructura de la realidad psíquica es sistémica(21).

En tanto que postura integradora, el emergentismo sistémico se opondría a la teoría de la identidad (que reduce la mente al cerebro), pero también al dualismo (al no aceptar el estatus ontológico privilegiado que concede a la mente). De la misma manera, no asumiría el reduccionismo fisicalista (al entender que la mente es un fenómeno estructural irreductible per se a una mera actividad cerebral que no parece explicar la complejidad de los procesos psíquicos conscientes). Sin embargo, pese a sus beneficios teóricos, algunos contemplan este posicionamiento como una forma sutil de dualismo, entretanto otros defienden que se trata de un monismo materialista suavizado que no otorga entidad propia a lo mental. El error de estas apreciaciones consiste en pensar, dentro del antiguo marco epistemológico y ontológico cartesiano, que el emergentismo sistémico es una 
postura "intermedia", o trata de rellenar un "hueco vacío", convirtiéndose así en una revisión del "interaccionismo" mente-cuerpo. Pero lo cierto es que el modelo emergentista no se interpone entre entidades, ni estima que exista vacío alguno, pues entiende que el dualismo es una ficción intelectual alimentada por una forma peculiar de argumentar. De hecho, el mentalismo (idealismo) y el fisicalismo (empirismo) ingenuos no solo son posturas complementarias, sino posiblemente ciertas en sus propios términos, en tanto que lecturas alternativas del mismo fenómeno(1).

Es poco probable que se pueda resolver un problema desde su negación. Y, en el caso de la cuestión del alma-espiritu-mente-conciencia, eso es lo que se ha tendido a hacer. No se afirma que el emergentismo sea la "panacea" que salva este asunto, ni se comete la ingenuidad de presuponer que sus variantes, cual sucede con el popperiano "Mundo 3 ", no posean aspectos revisables(22). Pero si se presta atención al modo en que buscan integrar el conocimiento presente, sí suponen una vía prometedora. No obstante, aun a pesar de la influencia indiscutible de la Teoría General de Sistemas en todos los entornos científico-tecnológicos, así como la indiscutida aceptación del evolucionismo como paradigma explicativo elemental de la diversidad de la vida, propuestas como la del emergentismo sistémico continúan sometidas a debate, cuando parecen la salida viable a un problema que quizá no exista más allá de la manera que se tiene de abordarlo.

En la medida en que la estructura del razonamiento humano es lineal, unidireccional y subjetiva, se presupone que lo real también funciona de tal modo, por lo que, de no mediar las adecuadas precauciones (la amenaza del "psicologicismo"), se generan teorías realmente curiosas (y falsas) acerca de la estructura del mundo, que dificultan comprender todo cuanto se sale de tal esquema. Lo cierto es que la causalidad opera antes de modos circulares e interactivos, que de forma lineal y unidireccional. Precisamente por ello tiene poco sentido enredarse en cuestiones acerca de qué fue antes, pues induce a posturas negacionistas que se apoyan en lo que podría considerarse "más importante", o "generatriz", en un momento dado, y no en el funcionamiento de la estructura sistémica del mundo(23). Al adoptar tales puntos de vista, se induce que, si una visión es "más correcta", la contraria es necesariamente "más falsa". Es indiscutible que el proceso de socialización implica distorsión de lo real, pues consiste en enseñar a las personas qué han de ignorar, así como qué han de aprender y comunicar, si de lo que se trata es de lograr el objetivo de una sociedad ordenada y coherente. Pero sería absurdo pretender que lo que no se puede (o debe) ver o saber en un momento dado simplemente no es real, si se asume que la realidad humana es cultural y, por ende, "construida" $(23,24)$.

\section{El acceso a "lo real"}

Lo que se denomina "realidad", y comprenderlo ha sido el mayor acierto del kantismo, es el resultado directo de elaboraciones psicofisiológicas construidas sobre los datos (siempre fragmentarios) que se toman de la experiencia sensible. No hay una genuina "realidad" fuera del propio sujeto. Posiblemente, el "ser consciente", al ocupar el centro de la vida psíquica, aleja a las personas de la comprensión de que la génesis de la conciencia es un proceso no consciente. No sucede que algo sensitivo y que es "solo" psicofisiológico se transmute en algo psicológico y que es "solo" mental. Ver las cosas así es la esencia misma del problema y el genuino error cartesiano. Entre un estado y el otro no hay un vacío absoluto, sino un continuo procesual, hecho ya postulado desde la neurología clásica $(8,12)$.

Sorprende que ya el tomismo, aun desde las limitaciones inherentes a la altura de su tiempo, sostuviera una versión consistente y productiva de esta misma intuición: la persona (entiéndase "persona" como "esta entidad consciente que soy") no podía ser solo alma, o solo cuerpo(2). La persona era el "compuesto" de ambos, en la medida que así se daba razón de la conexión entre el denominado psiquismo inferior (los sentidos) y el psiquismo superior (los procesos mentales). Así, se asumía la correspondencia entre los fenómenos psicológicos que constituyen la realidad íntima del sujeto y lo que acaecía en el exterior(25). Por supuesto, todo ello era posible porque el propio Dios garantizaba la correspondencia entre esos estados internos de la persona y el mundo circundante. Esto permite vislumbrar el problema de fondo: no es que esta panorámica no proponga un abordaje eficiente, 
sino que no parecen intelectualmente agradables los recursos disponibles para validarla.

Posiblemente, la esencia histórica del distanciamiento entre lo corporal y lo mental se reduce a algo tan básico como la creencia de que se está ante una cuestión de primogenitura teórica. $\mathrm{Mu}$ chos no estaban dispuestos a aceptar la estructura del argumento tomista, independientemente de su calidad explicativa, a causa de sus implicaciones. No se trataría tanto de que ofreciera una hipótesis sobre la cuestión intrínsecamente cuestionable, como de que permitiría la defensa de otras ideas paralelas, como la naturaleza "divina" de un "alma inmaterial” que justificaría la humanidad. El análisis del argumento en clave presentista impide comprender que la defensa de una posible "naturaleza divina" del alma, del espíritu, de la conciencia o de la mente, supone un planteamiento ontológico alternativo, ajeno por completo al devenir científico y sus presupuestos(2). Al fin y al cabo, la psicopatología moderna no ha dudado en sostener la idea (paralela a la descrita) de que en buena medida los trastornos mentales se definirían como relaciones "desajustadas" o "desintonizadas" entre el individuo y su entorno. Precisamente por ello, el idealismo kantiano, asumiendo esta estructura paradójica de la psique en la que se confrontan lo objetivo y lo subjetivo, aclaró que la razón humana está condenada a vivir rodeada de cuestiones a las que no puede responder, pero que tampoco puede ignorar(26).

Posiblemente, uno de los grandes problemas ideológicos de la ciencia contemporánea reside en que nunca ha terminado de confiar en el vigor del laicismo que la posibilitó. Advirtió pronto que, a fin de poder explicar "lo real" en términos racionales, razonables y operativos, debía apartarse de las influencias contaminantes de la religión, la metafísica y el misticismo(27). Tal prevención degeneró, con la secularización progresiva de Occidente, en una negación improductiva. La desconfianza en el poder genuino de la actividad científica para mantenerse al margen de las influencias religiosas, aunada a las presiones constantes de unas instituciones religiosas que se han sostenido históricamente, ocupando cuotas de poder temporal, condujo paulatinamente al científico hacia la pretensión de que la ciencia existe para refutar cualquier precepto que tenga un remoto viso de misticismo y/o dogma. Pero ese no es el tema de la ciencia, por lo que no sirve en forma alguna a tal proyecto negacionista(2).

Ocurre, como se apuntaba, que la psiquiatría y la psicología han asumido implícitamente el fondo del enfoque tomista, al convertir en uno de sus objetivos centrales la descripción, comprensión y terapéutica de los estados "alterados" de conciencia, en el sentido de "disfuncionales", a la hora de establecer conexiones fiables entre la información del mundo objetivo (externo) y las construcciones del mundo subjetivo (interno) (28). Un hecho que equivale a reconocer la existencia de ese continuo procesual que enlaza lo corporal y lo mental. Quizá, dado que en la vida diaria se asume la existencia de interacciones psicofísicas(29), se viva en el emergentismo sistémico de suerte natural y ocurra, a causa de las trampas y dificultades que se suscitan en la tarea misma de pensar, que se deje de serlo cuando se plantea la cuestión(28). Sucede entonces que, al resultar imposible ajustarse a hechos precisos, se opta por generar un patrón explicativo en términos de razón-objeto.

Un ejemplo de cómo se elaboran teorías acerca del funcionamiento de las cosas se presenta en un experimento que se desarrolló en la Universidad de Stanford(23). Se enfrentaba a los sujetos a un dispositivo equipado con una serie de 16 botones sin inscripción alguna, y cuya secuencia particular de pulsado se debía "aprender" para ir sumando puntos a un marcador. El jugador debía apretar los botones tentativamente para elaborar un modelo mental de la programación de la máquina. Cada vez que acertaba se escuchaba un zumbido y era recompensado. El secreto residía en que los zumbidos y las secuencias de botones eran completamente aleatorios y no seguían un patrón de contingencia, modificándose la frecuencia de señales de acierto en razón de un criterio aleatorio. Es decir, no había nada que aprender. Y es que la finalidad del experimento no era "ganar" o "encontrar patrones" (no los había), sino averiguar cómo las personas generan hipótesis en torno a los acontecimientos del mundo y cómo se convencen de que son ciertas una vez establecidas. El experimento concluía cuando, tras pedir al sujeto que explicara con detalle su particular teoría acerca del funcionamiento del dispositivo, el experimentador le mostraba que daba igual la hipótesis ela- 
borada, porque en realidad todas eran igualmente "válidas". Pero, confrontados con lo real, pocos eran los individuos que asentían. Habían estado realizando tan grandes esfuerzos para desarrollar un "constructo válido" acerca del funcionamiento de la máquina que, cuando habían creído encontrarlo, se aferraban a él con todas sus fuerzas. En algún caso de especial obstinación se hacía necesario que el experimentador levantara el panel con los botones, y mostrase que la máquina no tenía un mecanismo interno.

Sustancializar u objetualizar eventos para así poder "trabajarlos" no es intelectualmente eficiente. Todo experto en diseños experimentales conoce el hecho obvio de que objeto y proceso no son lo mismo. Pero pocas personas son especialistas en metodología de investigación y pueden precaverse ante tal contingencia. Los individuos sometidos a la "máquina” experimental presuponían que, en efecto, había un mecanismo bajo la carcasa que otorgaba sentido a todo cuanto sucedía en el exterior, pero su inexistencia motivaba que cualquier teoría fuese inducida por una ilusión de entidad e incurría en sesgo de circularidad: si esto es una máquina responde a ciertas instrucciones programadas $y$, por lo que su funcionamiento solo tiene sentido si es una máquina(23). Al trasladar estas reflexiones a nuestro contexto, se entiende que pensar cerebro y conciencia en términos de objeto es ineficaz. De hecho, es improbable que las neuronas sean la unidad de experiencia consciente, y no hay motivo alguno para dudar de que la conciencia sea un proceso emergente de la actividad de los circuitos neurales, con los que ya no se identificaría(30).

\section{Conclusión: una cuestión ético-moral}

Ferdinand von Schirach relata la historia de un tal Feldmayer, al que hubo de representar ante los tribunales alemanes(31). Este hombre obtuvo la plaza de vigilante que ofrecía un museo de arte. Sin embargo, por un error burocrático, su ficha fue excluida del archivo de rotaciones de los empleados, destinado a modificar su destino cada seis semanas. Todo el mundo se olvidó de Feldmayer y él, por desconocimiento, nunca se quejó. Simplemente siguió acudiendo durante años a su aburrida ocupación, una sala sin apenas visitantes, en cuyo centro se encontraba la estatua de un espinario.
Al fin, y dado que el museo no cambiaba nunca, fue el museo quien lo cambió a él. Su régimen de vida, sus ocupaciones, costumbres e incluso el orden y apariencia de su domicilio. Y así, ocho años después, se formuló la pregunta fatídica: “'habrá logrado encontrar el chico la espina que se le clavó en la planta del pie?" Ese fue el desencadenante de una locura progresiva que no solo concluyó con la destrucción de la escultura, sino que también lo sumió en un trastorno mental.

Este relato ejemplifica algo que se asume con normalidad en la vida diaria: la "facilidad" con la que una circunstancia que comienza siendo de orden enteramente psicofisiológico (la relación psicoestimular con una circunstancia externa reiterada), desciende lentamente desde el materialismo de lo mecánico y medible, atraviesa un valle degenerativo, y luego asciende hacia el trastorno psíquico (el desajuste del sujeto como entidad psicológica autoconsciente con su circunstancia externa), y en tanto que proceso plantea consecuencias psicosociales, morales y éticas: ¿tenía Feldmayer "derecho" a destruir el espinario? ¿Es el mismo espinario que veía Feldmayer el que vería cualquier otra persona? ¿Qué garantiza que todo el mundo vea "el mismo" espinario? ¿Cómo es el "mundo objetivo" más allá del "mundo psíquico"? ¿Cómo determinar un criterio estándar que permita la convivencia intersubjetiva de los seres humanos? ¿Cómo garantizar que la sociedad, la cultura, el conocimiento, la realidad misma, en tanto que estructuras integradoras y vertebradoras de la existencia humana, sean objetivamente viables y regulables?

Se advierte que hay en juego mucho más que un debate entre materialismo e idealismo, o una batalla colateral e irrelevante entre ciencia, filosofía y religión que acaso tenga poco sentido epistémico librar. Por supuesto, se ha perdido esa inocencia intelectual de la Antigüedad, que permitía al aristotelismo negar la existencia del "mundo de las ideas" platónico y, sin disonancia cognitiva alguna, defender que todas las esferas del cosmos estaban empujadas por el movimiento constante de un gigantesco y cuasi divino "motor inmóvil". El camino de la modernidad-posmodernidad ha desembocado en un positivismo cientificista y un control tecnocrático de las "cosas" que ha inducido un extraño sistema de "pensamiento trinchera". Así, el problema de Feldmayer, redefinido en tér- 
minos ético-morales, nos ubica ante la disyuntiva de juzgarlo "como si" realmente pudiera decidir sobre sus actos (lo cual lo transforma inevitablemente en culpable), o bien "como si" estuviera sometido al ignoto control de una maquinaria cerebral desajustada que lo determinó a comportarse como lo hizo (y entonces no podría ser en modo alguno responsable, sino una víctima determinada por circunstancias perversas). Y, de este modo, se reedita el problema cartesiano que se imagina superado.

Volvamos al popperiano tema del "Mundo 3". Aquí la estrategia para la resolución del conflicto consistió en saltar por encima de la consideración clásica del tema para redefinir qué era la mente y en qué consistiría "pensar". Para ello, huyó de los sustancialismos tópicos en este ámbito e, inspirándose en propuestas como la del inconsciente colectivo junguiano y la construcción social de la conciencia vigotskyana, se concentró en lo simbólico y su importancia tanto para la propia mente, como para el modo en que ello afectaba a la construcción y comprensión de la realidad externa(32). Se trataba de generar una perspectiva del problema irreductible a meras premisas fisicalistas, conductistas o psicologicistas. Se rompía el círculo, asumiendo que el mundo, la cultura y la sociedad ya estaban ahí dadas, en tanto que construcción humana, "antes" de que cada sujeto particular naciera. Así, se haría cargo de un conocimiento, un lenguaje y unos símbolos (Mundo 3) previamente elaborados, y que se moverían de acuerdo con sus propios principios(22). Este "hacerse cargo" sería siempre implícito, si bien se viviría en la permanente ilusión de que todo cuanto sabe, se cree o se imagina es personal, ajeno al magma cultural del que se alimenta. Precisamente por esto no cabrían las respuestas reduccionistas al caso Feldmayer, siendo fácil advertir que tienen algo disfuncional: toda respuesta fisicalista (mentes, cuerpos, neuronas, circuitos, tránsitos bioquímicos) implica necesariamente determinación de objeto y, con ello, Feldmayer no pudo elegir, estando condenado sin esperanza a comportarse de manera antisocial; pero cualquier respuesta de orden mentalista (almas, conciencias, espíritus) implicaría un problema no menor, ya que nos situaría ante la idea de que Feldmayer es un malvado que eligió hacer lo que hizo. Así es como induce el control totalitario y estigmático que promete todo esencialismo: si no cabe perseguirlo por su maldad, cabría hacerlo para protegerse de sus determinaciones(33).

Que el juez optara por condenar al museo, al no cumplir con sus responsabilidades, nos habla del modo en que se solventa esta dicotomía en la vida diaria, y que no deja de asumir un enfoque sistémico-emergentista de fondo. Se buscan soluciones ético-morales de corte procesual, pues se advierte un decalaje insuperable entre la racionalidad científica y la racionalidad ética. Quizá ocurra que el problema de la mente, al filtrarse por el marco explicativo impuesto por los modelos de corte esencialista, se ve impulsado hacia la cuestión bioética que nunca ha dejado de ser en el fondo, y que se ha leído en infinidad de claves a lo largo de la historia: pnéuma, humoralismo, fisiognomía, craneometría, mecanicismo, frenología, eugenesismo y etcétera $(2,16,17)$. No es que se pueda o no prescindir de cierto componente "irreductible" a la hora de definirnos como humanos, es que siempre que hemos prescindido de él hemos tenido que enfrentarnos a terribles consecuencias sociopolíticas. No es que el ser humano no "pueda" ser relatado en un futuro más o menos lejano en términos reduccionistas. La cuestión es si, aun siendo posible, "debería" permitirse esa clase de relato, ignorando por completo sus implicaciones, pues uno de los más graves problemas a los que se enfrenta la comunidad científica en el siglo XXI no es determinar si algo "puede" o "no puede" hacerse, sino el de decidir qué "debe hacerse", más allá de cálculos de costes y beneficios. Entender que cualquier control ético sobre lo que se dice, lo que se hace o lo que se piensa puede reducirse a aparato, cálculo probabilístico o designio ideológico, implica abrir las puertas a la tentación del totalitarismo(34).

No se trata de renunciar, absurdamente, a la comprensión de cómo el cerebro interviene en la producción de constructos psicológicos. Más bien se trataría de comprender que, aun haciendo todo lo posible por desentrañar esas cuestiones, nunca podremos estar seguros de haber alcanzado su fundamento último, en la medida que, por su propia definición, esto no es posible: todo constructo psicológico, en el mejor de los casos, solo puede ser inferido del comportamiento, pero no identificado con el mismo o con una cadena de eventos 
psicofisiológicos específicos(30). Lo psicológico es un proceso en constante construcción-reconstrucción, no solo intervenido por variables anatomofisiológicas y bioquímicas, sino también por las experiencias y contextos que se viven y que lo modulan, así como por las condiciones culturales en las que esto se produce. Lo psicológico "se hace" y "se rehace" (31). La psicología del otro puede ser inferida, estudiada a través de sus conductas, analizada en las impresiones que suscita, pero nunca comprendida hasta sus últimas consecuencias, que, en el mejor de los casos, son "estados internos". Se trata de la clásica situación paradójica que se vive en toda terapia y que es el caballo de batalla de la psicología clínica: el estándar de salud y bienestar que pretende el especialista para el común de sus pacientes, cifrado en la reducción del síntoma, rara vez coincide con el que el paciente en particular pretende para sí mismo, cifrado en la esperanza de felicidad y mejora personal(35). Se impone, pues, un abordaje razonablemente ético de esta cuestión que la mantenga en los márgenes de un humanismo heterogéneo, en la misma medida que la protegerá de las siempre sospechosas tentaciones del totalitarismo homogeneizador y que, en suma, acepte que este proceso susceptible de comprensión científica que es la conciencia — alma, mente, cuerpo- es tan individual en sus manifestaciones, como general en sus principios; tan único en sus consecuencias como común en su génesis; tan mensurable en relación a sus códigos de especie como incuantificable en relación al individuo; tan accesible en lo que tiene de objetivo como inasible en lo que tiene de subjetivo.

Declaración de conflictos de interés: Los autores declaran la inexistencia de conflictos de interés en relación con el contenido del presente artículo. 
Repensando las consecuencias bioéticas del monismo y el dualismo - Francisco López-Muñoz, Francisco Pérez-Fernández

\section{Referencias}

1. Searle J. Mentes, cerebros y ciencia. Barcelona: Cátedra; 1994.

2. López-Muñoz F, Pérez-Fernández F. La barca de Caronte. El largo viaje histórico del alma a través del pensamiento, la ciencia y la medicina. Madrid: Delta Editorial; 2020 (en prensa).

3. Comte A. Discurso sobre el espiritu positivo. Madrid; Alianza; 1980.

4. Damasio A. El error de Descartes. Barcelona: Crítica; 1996.

5. Cajal SR. Prólogo. En: Maestre T. Introducción al estudio de la psicología positiva. Madrid: Librería-Editorial Bailly-Baillière e Hijos; 1905: I-XXI.

6. López-Muñoz F, Álamo C, Rubio G. The neurobiological interpretation of the mental functions in the work of Santiago Ramón y Cajal. Hist Psychiatr. 2008; 19: 5-24.

7. Nietzsche F. El nacimiento de la tragedia (trad. Andrés Sánchez Pascual). Madrid: Alianza; 2012.

8. Nardone G. Siete cuestiones esenciales para conocer al ser humano. Barcelona: Plataforma Editorial; 2019.

9. Wittgenstein L. Lecciones sobre filosofía de la psicología. Madrid: Alianza; 2004.

10. Wright-Carr D. La hipótesis Sapir-Whorf: una evaluación crítica. Caleidoscopio. Rev Sem Cienc Soc Hum. 2007; 11(22): 7-26.

11. Henríquez RA. El efecto del dualismo filosófico en el problema de la ética animal. Acta Bioethica 2014; 20: 109-17.

12. Sacks O. El hombre que confundió a su mujer con un sombrero. Barcelona: Anagrama; 2002.

13. Foucault M. Historia de la clinica. Una arqueología de la mirada médica. Madrid: Siglo XXI; 2009.

14. Habermas, J. Conocimiento e interés. Barcelona: Taurus; 1992.

15. Kater MH. Doctors under Hitler. Chaper Hill (NC): University of North Carolina Press; 1989.

16. López-Muñoz F, Álamo C, García-García P, Molina JD, Rubio G. The role of psychopharmacology in the medical abuses of the Third Reich: from euthanasia programmes to human experimentation. Brain Res Bull. 2008; 77: 388-403.

17. López-Muñoz F, Álamo C. Psychotropic drugs research in Nazi Germany: The triumph of the principle of malfeasance. Acta Neuropsychiatr. 2009; 21: 50-3.

18. Sperber I. Fashion in Science: Opinion, Leaders and Collective Behavior in Social Science. Minneapolis (MN): University of Minnesota Press; 1990.

19. Carpintero H. Historia de las ideas psicológicas. Madrid: Pirámide; 1996.

20. LeDoux J. El cerebro emocional. Barcelona: Editorial Planeta; 1999.

21. Beorlegui C. Los emergentismos sistémicos: Un modelo fructífero para el problema mente-cuerpo. Pensamiento 2006; 62(234): 391-439.

22. Henríquez Garrido RJ. Popper “Bouvard y Pécuchet”. Nueva refutación del Mundo 3. Logos. An Sem Metafísica 2002; 35 : $331-46$.

23. Watzlawick P, Weakland JH, Fisch R. Cambio. Formación y solución de los problemas humanos. Barcelona: Herder; 1989.

24. Berger P, Luckmann T. La construcción social de la realidad. Buenos Aires: Amorrortu Editores; 1968.

25. Aquino ST. Suma Teológica. Madrid: BAC; 2014, I, Cuestión 75, artículo 2.

26. Atencia Páez JM. La imposibilidad de (no) creer. Contrastes. Rev Int Filosofia 2013; XVIII: 201-10.

27. López-Piñero JM, Navarro V, Portela E. La revolución científica. Madrid: Historia 16; 1989.

28. Kutschera Fv. El problema cuerpo-alma. Mente y Cerebro 2003; 4: 60-5.

29. Davidson D. Essays on Actions and Events. Oxford: Oxford University Press; 1980.

30. Kolb B, Whishaw IQ. Cerebro y conducta. Una introducción. Madrid: McGraw-Hill Interamericana; 2002.

31. Schirach Fv. Crimenes. Barcelona: Publicaciones y Ediciones Salamandra, S.A.; 2013.

32. Mendoza García J. Otra mirada: La construcción social del conocimiento. Polis 2015; 11: 83-118.

33. Foucault M. Vigilar y castigar. Nacimiento de la prisión. Madrid: Siglo XXI Editores; 1976.

34. López Moratalla N. Biología y ética de la bioética: La urgente necesidad de realismo. Cuadernos Bioética 2013; XXIV (2a): 251-64.

35. Szmulewicz T. La persona del terapeuta: eje fundamental de todo proceso terapéutico. Rev Chil Neuropsiquiatr. 2013; 51: 61-9.

Recibido: 3 de marzo de 2020

Aceptado: 20 de marzo de 2020 